\title{
Bilateral Sixth Nerve Palsies Possibly Associated with Arsenic Trioxide in Acute Promyelocytic Leukaemia
}

\author{
Pusem PATIR ${ }^{1}$, Merve OYTUN ${ }^{2}$, Ahmet A. OZLUK ${ }^{2}$, Guray SAYDAM${ }^{1}$, \\ Ayhan DONMEZ ${ }^{1}$, Murat TOMBULOGLU ${ }^{1}$ \\ ${ }^{1}$ Ege University, Faculty of Medicine, Department of Hematology \\ ${ }^{2}$ Ege University, Faculty of Medicine, Department of Internal Medicine, Izmir, TURKEY
}

\section{Dear Editor,}

Acute promyelocytic leukemia (APL) is a unique subtype of acute myeloid leukemia (AML) characterized by specific morphological and cytogenetical aberrations, and a potentially life-threatening coagulopathy. ${ }^{1-3}$ APL is defined by a specific balanced translocation, $\mathrm{t}(15 ; 17)$, resulting in the fusion of PML (promyelocytic leukemia) and RAR $\alpha$ (retinoic acid receptor- $\alpha$ ) genes. This fusion provides an aberrant, oncogenic protein (PML-RAR $\alpha$ ) that blocks myeloid differentiation at the promyelocyte stage. , $^{4}$ APL is a rare disease (approximately $1200-1500$ cases per year in the United States), accounting for approximately $10-15 \%$ of all the AML cases. ${ }^{6}$ All trans retinoic acid (ATRA) and arsenic trioxide (ATO) are the cornerstones of APL therapy, and have dramatically improved outcomes. ATRA in combination with ATO or anthracyclines has been used for the induction treatment of APL, and the rate of complete remission may be as high as $90 \%$ after this treatment. ${ }^{7,8}$

A 30-year-old female patient was admitted to the hematology department in November of 2014. She was experiencing fatigue, weight loss, hemoptysis and frequent infections. The physical examination revealed normal. Pancytopenia (hemoglobin $11.8 \mathrm{~g} /$ $\mathrm{dL}$; leukocytes $1600 / \mathrm{mm}^{3}$; platelet count $36000 / \mathrm{mm}^{3}$ ) was determined in complete blood count (CBC) and atypical promyelocytic cells with Auer rods were detected on the peripheral blood smear. Bone mar- row aspiration and biopsy revealed a hypercellular marrow with $40 \%$ promyelocytes containing Auer rods. Flow cytometry was performed to confirm the presence of myeloid blasts (CD34, HLA-DR were negative; CD13, CD33 were positive). Fluorescent in situ hybridization (FISH) and real-time fluorescence quantitative polimeraze chain reaction (RT-PCR) analysis were performed in the patient's bone marrow and confirmed PML-RAR $\alpha \mathrm{t}(15,17)$.

After a diagnosis of APL was confirmed, ATO was choosen as optional treatment modality and since it was not available in market, an off-label application was delivered to the Ministry of Health $(\mathrm{MoH})$. Since it would take time to have permission from $\mathrm{MoH}$, the induction treatment was started with ATRA as a single agent. From December 1, 2014 to December 14, 2014, she was treated with ATRA $45 \mathrm{mg} / \mathrm{m}^{2} /$ day (70 mg/day) for 14 days. On day 15 of the ATRA treatment, she developed a fever, a rapid rise in the leukocyte, and pleuritic chest pain. Firstly, ATRA syndrome was considered and the ATRA was interrupted. She was treated with dexamethasone $20 \mathrm{mg} / \mathrm{d}$ for 7 days and then it was discontinued gradually. From December 23, 2014 to December 29, 2014, she was re-treated with ATRA at $45 \mathrm{mg} / \mathrm{m}^{2} /$ day $(70 \mathrm{mg} /$ day) as a single agent for 7 days. After, from December 30, 2014 to January 3, 2015, she was treated with ATRA at $45 \mathrm{mg} / \mathrm{m}^{2} /$ day (70mg/day) and ATO at 0.15 $\mathrm{mg} / \mathrm{kg} /$ day (10 mg/day) for 5 days. 
On day 6 of the ATO treatment, hepatotoxicity was observed and improved after the discontinuation of ATRA and ATO and hepato-protective therapy containing N-Acetyl Cysteine. From January 12, 2015 to January 18, 2015, ATRA at $40 \mathrm{mg} /$ day and ATO at $0.075 \mathrm{mg} / \mathrm{kg} /$ day $(5 \mathrm{mg} /$ day) as a half of a total dose were restarted in combination with methylprednisolone at $40 \mathrm{mg} /$ day for 7 days. From January 19, 2015 to February 15, 2015, ATRA at $40 \mathrm{mg} /$ day and ATO at $5 \mathrm{mg} /$ day were continued. For the remission control, FISH and RT-PCR analysis were performed on the patient's bone marrow, and results confirmed complete remission.

On February 16, 2015, the consolidation treatment was started, and she was treated with ATRA at 40 $\mathrm{mg} /$ day for 15 days and ATO at $5 \mathrm{mg} /$ day for 5 days per week. On the first day of the treatment, she developed sudden blurred vision and diplopia. She was consulted by an ophthalmologist and neurologist. The fundoscopic examination was normal. The neurological examination showed restricted lateral movement of both eyeballs and both apparent abducens nerve palsies. Any other possible findings consistent with peripheral neuropathy were not detected. The neurologocial and opthalomological examinations confirmed isolated bilateral 6th nerve palsies, more prominent on the left side, which were at onset, firstly suspected to be caused by isolated leukemic infiltration. The cerebrospinal fluid (CSF) examination and brain magnetic resonance imaging (MRI) were performed in terms of nerve involvement and revealed normal laboratory analysis and imaging. Thus, 6th nerve palsies were considered to be caused by a drug reaction as an adverse event. On February 20, 2015, ATRA and ATO treatment were stopped and then she was monitored. Her complaints completely ceased, and it was decided to replace the consolidation treatment. On March 5, 2015, she was treated with ATRA at $40 \mathrm{mg} /$ day for 15 days and idarubicin at $5 \mathrm{mg} / \mathrm{m}^{2}$ for 4 days quarterly. The consolidation treatment with ATRA and idarubicin was continued seamlessly; therefore, the adverse ocular reaction was considered to be possibly associated with ATO.

ATO is now a standard drug in the treatment of newly diagnosed or relapsed APL. Treatment with ATO should be monitored carefully due to its po- tentially severe adverse effect profile. Fluid retention, differentiation syndrome, peripheral sensorial neuropathy, and electrocardiographic abnormalities may be observed as ATO's side effects during newly diagnosed APL patients' induction treatment. ${ }^{9}$ To our knowledge, bilateral sixth nerve palsies have not been previously reported. We detected the chronological relationship, regarding to the onset of ocular symptoms after 40 days of treatment (total dose of ATO was $275 \mathrm{mg}$ ), the improvement of ocular symptoms was observed 12 days after discontination of ATRA and ATO. Then consolidation treatment was started as ATRA and idarubicin but ocular symptoms were not observed again. So the symptoms were suggestive of the role of ATO, which is known to cause peripheral neurotoxicities. For our case, all other potential reasons of isolated cranial nerve palsy were exclude by CSF analysis and MRI. Peripheral neuropathy is reported in up to $10 \%$ of ATO treated patients. ${ }^{10,11}$ as a neurological side effect. In addition, Thery et al. presented optical neuropathy possibly related to ATO during APL tretment. ${ }^{12}$ Mechanism of ATO's neurotoxicity has not discovered yet. In literature, sciatic nerve of rats exposed to ATO were studied and propounded toxicity against neurofilaments bonded with sulfuryl group. ${ }^{13}$

The blood brain barrier prevents the penetration of heavy metals, including ATO, and protects the central nerve system (CNS). Therefore, CNS side effects are not usually expected during ATO therapy. The entry of the ATO into the CNS however, may occur when the blood brain barrier is disrupted. In a case of meningeal relapse of APL treated with oral-ATO, and the penetration of ATO into the CSF to therapeutically meaningful levels has been observed. ${ }^{14}$

Unexplained strabismus and diplopia should be evaluated as a potential sign of CNS involvement and initially conventional imaging, and a CSF examination should be performed. If the CNS involvement of APL is not detected, sixth nerve palsy can be considered to be caused by a drug reaction.

Herewith, a thorough understanding of the safety and potential side effects of ATO as a therapeutic agent is necessary in order to minimize its toxic complications. In cases with cranial nevre palsy 
under the treatment of ATO, after a detailed neurological examination, including MRI and CSF analysis, potential ATO-side effects should be considered.

\section{REFERENCES}

1. Bennett JM, Catovsky D, Daniel MT, et al. Proposals for the classification of the acute leukaemias: French-American-British (FAB) co-operative group. $\mathrm{Br} \mathrm{J}$ Haematol 33: 451-458, 1976.

2. Bennett JM, Catovsky D, Daniel MT, et al. A variant form of hypergranular promyelocytic leukaemia (M3). Br J Haematol 44: 169-170, 1980.

3. Tallman MS, Kwaan HC. Reassessing the hemostatic disorder associated with acute promyelocytic leukemia. Blood 79: 543553, 1992.

4. Rowley JD, Golomb HM, Dougherty C. 15/17 translocation, a consistent chromosomal change in acute promyelocytic leukaemia. Lancet 1: 549-550, 1997.

5. Grignani F, Ferrucci PF, Testa U, et al. The acute promyelocytic leukemia-specific PML-RAR alpha fusion protein inhibits differentiation and promotes survival of myeloid precursor cells. Cell 74: 423-431, 1993.

6. Tallman MS, Altman JK. Curative strategies in acute promyelocytic leukemia. Hematology Am Soc Hematol Educ Program 1: 391-399, 2008.

7. Iland HJ, Bradstock K, Supple SG, et al. All-trans-retinoic acid, idarubicin, and IV arsenic trioxide as initial therapy in acute promyelocytic leukemia (APML4). Blood 120: 1570-1580, 2012.

8. Lo-Coco F, Avvisati G, Vignetti M, et al. Retinoic acid and arsenic trioxide for acute promyelocytic leukemia. N Engl J Med 369: 111-121, 2013.
9. Ravandi F, Estey E, Jones D, et al. Effective treatment of acute promyelocytic leukemia with all trans retinoic acid, arsenic trioxide, and gemtuzumab ozogamicin. J Clin Oncol 27: 504510, 2009.

10. Lazo G, Kantarjian H, Estey E, et al. Use of arsenic trioxide (As2O3) in the treatment of patients with acute promyelocytic leukemia: the M.D. Anderson experience. Cancer 97: 22182224, 2003.

11. Ohnishi K, Yoshida H, Shigeno K, et al. Arsenic trioxide therapy for relapsed or refractory Japanese patients with acute promyelocytic leukemia: need for careful electrocardiogram monitoring. Leukemia 16: 617-622, 2002.

12. Thery JC, Jardin F, Massy N, et al. Optical neuropathy possibly related to arsenic during acute promyelocytic leukemia treatment. Leuk Lymphoma 49: 168-170, 2008.

13. Vahidnia A, Romijn F, Tiller M, et al. Arsenic-induced toxicity: effect on protein composition in sciatic nerve. Hum Exp Toxicol 25: 667-674, 2006

14. Au WY, Tam S, Fong BM, Kwong YL. Elemental arsenic entered the cerebrospinal fluid during oral arsenic trioxide treatment of meningeal relapse of acute promyelocytic leukemia. Blood 107: 3012-3013, 2006.

\section{Correspondence}

Dr. Pusem PATIR

Ege Üniversitesi Tip Fakültesi

Hematoloji Anabilim Dali

35100 Bornova, IZMIR / TURKEY

Telephone: (+90-232) 3903540

Fax: (+90-232) 3903530

e-mail: pusemp@yahoo.com 